\title{
Oral fluorescein and cystoid macular oedema: detection in aphakic and pseudophakic eyes
}

\author{
MARK J. NOBLE, HUNG CHENG, AND PAUL M. JACOBS \\ From the Eye Hospital, Walton Street, Oxford
}

SUMMARY The ingestion of oral fluorescein in 38 consecutive cases 6 to 7 weeks after cataract surgery with and without iris clip lens implantation permitted satisfactory fluorography to detect all cases of clinical cystoid macular oedema. There were no adverse reactions from any test subject.

The reported incidence of cystoid macular oedema (CMO) after cataract surgery varies widely. In part this is because the term CMO has been used to describe both an appearance on fluorescein angiography and a clinical syndrome occurring after cataract surgery where impairment of vision is associated with angiographic changes at the disc and macula (Irvine-Gass syndrome).

Studies of consecutive cases performed during the first 2 months after cataract surgery have shown that the incidence of $\mathrm{CMO}$ may be in as high a range as $46.7 \%$ ' to $68 \%$. . $^{2}$ However, these figures refer to a continuum of angiographic abnormalities varying from slight leakage from perifoveal capillaries to the petalloid appearance typical of CMO. The incidence of CMO associated with reduced vision is much lower. ${ }^{2+}$

There are drawbacks in the use of intravenous fluorescein angiography to diagnose CMO. Many patients find it unpleasant to have the injection, which must be given by a doctor. Adverse reactions to sodium fluorescein occur in $0.6 \%$ of patients, ${ }^{5}$ and a rapid intravenous injection of the drug may cause respiratory obstruction, cardiac arrest, and death.

Kelly and Kincaid have reported that the oral administration of fluorescein may yield satisfactory late fluorograms in conditions where permeability abnormality is being investigated, such as CMO." Our own observations on selected patients support this observation.

The purpose of this study was to determine the value of oral fluorescein in detecting CMO after cataract surgery, which included both simple intracapsular extraction and lens implantation.

Correspondence to Hung Cheng. FRCS. The Eyc Hospital, Walton Strect, Oxford, OX2 6AN.

\section{Materials and methods}

Thirty-eight patients were recruited after lens extraction for senile cataract by the same surgeon (HC). Thirteen eyes received straightforward intracapsular extraction, 12 eyes received intracapsular extraction and Federov- 1 lens implants, and 13 eyes received extracapsular extraction and Binkhorst iridocapsular implants.

Seven weeks after surgery the patients were refracted by a hospital based optician and the best corrected distance acuity was recorded. The pupil of the operated eye was then dilated with guttae phenylephrine $10 \%$. All subjects were given $1.25 \mathrm{~g}$ of sodium fluorescein flavoured with lemon to drink. Photography was carried out 45-60) minutes after intake of fluorescein with a Zeiss fundus camera and RAR film (Kodak RAR type no. 2498). Red-free photographs were taken before the fluorogram with standard filter pairs. After photography the pupil dilatation was reversed with guttae thymoxamine $0.5 \%$. Patients with lens implants were kept for 20-30 minutes to observe the effect on the pupil before being allowed home. No adverse reaction to oral fluorescein was observed.

Table 1 Quality of red-free photographs according to the type of surgery

\begin{tabular}{lccll}
\hline & Good & Fair & Poor & Not done \\
\hline I/C & 9 & 1 & 1 & 2 \\
I/C+Fed & 10 & 0 & 0 & 2 \\
E/C+Bink & 8 & 3 & 1 & 1 \\
Total & 27 & 4 & 2 & 5 \\
\hline
\end{tabular}

$I / C=$ Intracapsular extraction. $I / C+F e d=$ Int racapsular extraction + Federov implant. E/C +Bink = Extracapsular extraction +iridocapsular implant. 
Table 2 Eight of 38 patients with positive or doubtful fluorograms for CMO after oral fluorescein

\begin{tabular}{lllll}
\hline Result & $\begin{array}{l}\text { Quality of } \\
\text { red-free }\end{array}$ & $\begin{array}{l}\text { Type of cataract } \\
\text { surgery }\end{array}$ & $\begin{array}{l}\text { Visual acuity } \\
\text { at } 7 / 52\end{array}$ & Fluorescein angiography and clinical features \\
\hline Positive & Good & Federov & $6 / 24$ & Typical \\
& Good & Binkhorst & $6 / 12$ & Typical \\
Doubtful & Good & Binkhorst & $6 / 12$ & CMO on oral angiography confirmed hy IV angiography \\
& Good & Binkhorst & $6 / 6)$ & Diabetic maculopathy \\
& Good & Gindow defect below fovea \\
& Good & Binkhorst & $6 / 6$ \\
& Fair & $6 / 9$ & These patients have achicved persistently good \\
& Good & I/C & $6 / 9$ \\
\hline
\end{tabular}

Federov = Intracapsular cataract extraction with implantation of a Federov 1 type lens implant. Binkhorst= Extracapsular cataract extraction with implantation of a Binkhorst iridocapsular implant. $\mathrm{I} / \mathrm{C}=$ Intracapsular cataract extraction without lens implantation.

After being developed the films were observed and reported on without reference to the patient's treatment or visual acuity. The quality of the red-free photographs was graded into 3 categories-'good', 'fair', or 'poor'- depending on the clarity of the disc and vessels on the film. The quality of the fluorograms was similarly graded, and the photographs were recorded as showing 'definite CMO,' 'macular dye leakage not typical of $\mathrm{CMO}$, or 'being within normal limits.'

\section{Results}

Five of the 38 patients did not have red-free photographs. The grading of red-free photographs according to treatment groups is shown in Table 1 .

Three eyes $(7.9 \%)$ had definite evidence of $\mathrm{CMO}$ on the fluorograms. All 3 patients had a visual acuity of 6/12 or worse at the time of fluorography (Table 2).

Five eyes $(13 \cdot 2 \%)$ had fluorograms which were abnormal though not typical of CMO. One eye had diabetic maculopathy visible ophthalmoscopically. One eye showed a 'window' defect below the fovea which was visible as an area of pigment epithelial atrophy on the red-free photograph. The other 3 patients had a slight increase in fluorescence at the macula which was difficult to differentiate from normal background fluorescence. All of these patients except the first with diabetic maculopathy had vision of $6 / 9$ or better without clinical evidence of CMO (Table 2). They have all maintained good vision for over one year.

Thirty eyes $(78.9 \%)$ showed no evidence of fluorescein leakage in the macular area. All of these patients had vision of $6 / 9$ or better without clinical evidence of $\mathrm{CMO}(10=6 / 5,12=6 / 6,8=6 / 9)$.

All patients who had a positive or doubtful fluorogram had red-free photographs of 'good' or 'fair' quality. Of the 30 patients with negative fluorograms 2 had 'poor' quality red-free photographs prior to fluorography. In both these patients the quality of the fluorogram was 'poor'. As both patients had vision of
$6 / 9$ or better the fluorograms were not repeated. In some cases, particularly those with 'iris clip' lens implants which may make full pupillary dilatation hazardous, it may be difficult to obtain good quality fundus photographs. Where the red-free photographs show good fundus detail, it can be assumed that it is possible to obtain a fluorogram of good quality. However, where the red-free picture is missing or poor, absence of fluoroscopic appearance of CMO cannot be regarded as evidence of exclusion of the condition.

\section{Discussion}

Sodium fluorescein is rapidly absorbed from the stomach, and plasma concentrations reach a maximum within 1 hour of ingestion if the patient has an empty stomach. ${ }^{7}$ Fig. 1 shows fluorograms taken $15,30,45$, and 60 minutes after oral ingestion of $1.25 \mathrm{~g}$ of fluorescein by a patient with marked CMO. All fluorograms showed dye leakage at the disc and macula.

Although full pupil dilatation was not achieved in the majority of eyes with iris-clip lenses, it was possible to get adequate views of the fundus, and this is supported by the high proportion of 'good' red-free photographs obtained (Table 1).

Four patients in this study had a visual acuity of $6 / 12$ or worse at 6 to 7 weeks after surgery. One had diabetic maculopathy which presented as diffuse fluorescein leakage on the fluorogram. The other 3 patients all had oral fluorograms showing macular leakage which was typical of CMO.

The incidence of CMO was much lower in our series than in other studies of consecutive cases. While our patients may have a truly low incidence, it is notable that oral fluorescein is less sensitive in the detection of angiographic CMO.

Whether the Irvine-Gass syndrome or clinical aphakic cystoid macular oedema represents a more severe form of a spectrum of vascular disturbances of the macula or whether there are other factors 


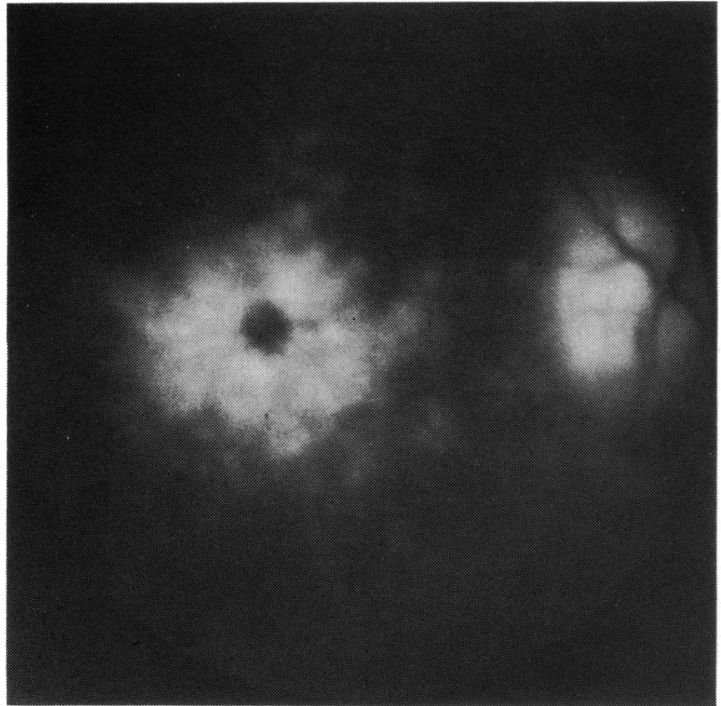

Fig. 1A 15 minutes afteringestion.

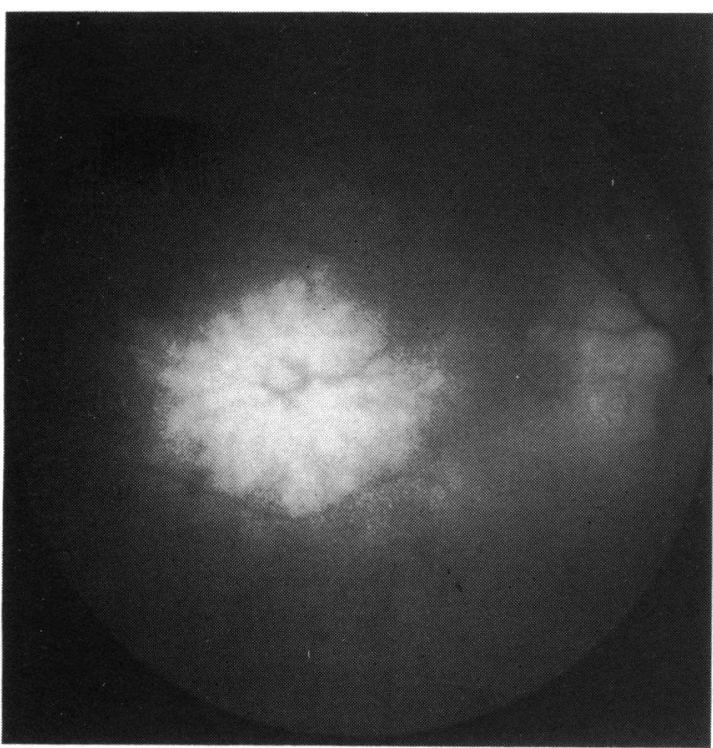

Fig. 1C 45 minutes afteringestion.

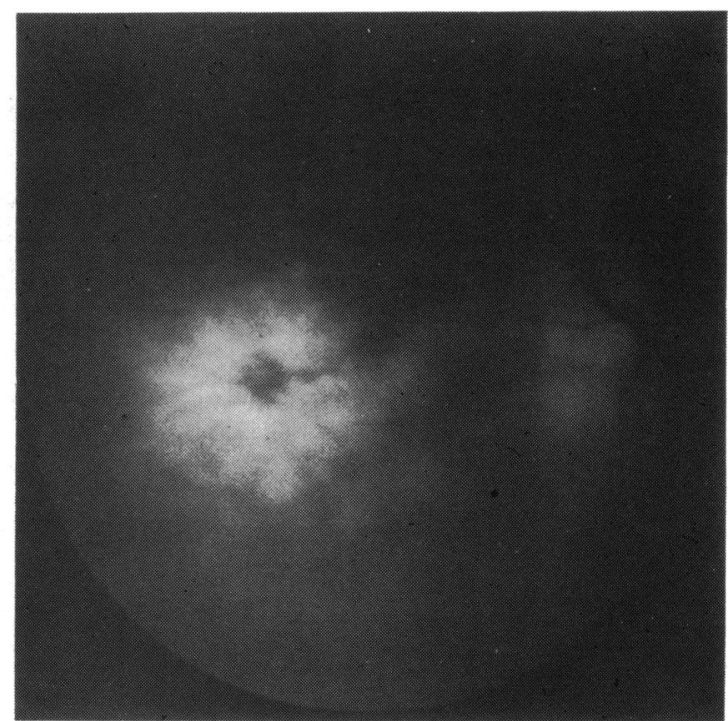

Fig. 1B 30 minutes afteringestion.

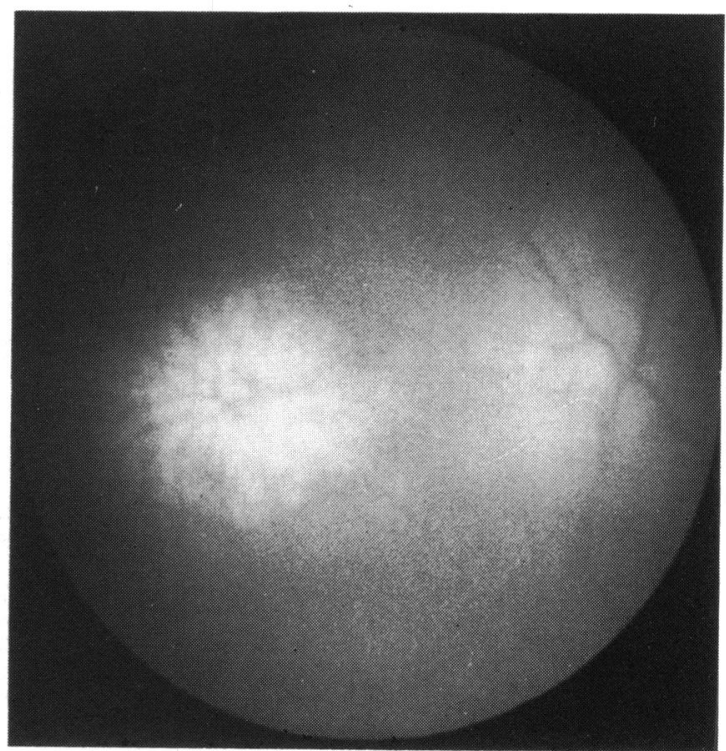

Fig. 1D 60 minutes afteringestion.

Fig. I Fluorogram of an eye with (MO taken at (A) 1.5, (B) 30, (C) 45, and (D) 60) minutes afier oral ingestion of $1.25 \mathrm{~g}$ of fluorescein.

operating in patients who suffer visual loss is not yet clear. Hitchings found that the visual symptoms and severity of angiographic disturbance were not related,' although Miyake's classification appears to contradict this observation. ${ }^{2}$ In clinical practice it is the patients with visual loss in whom it is most important to define the pattern of macular changes, and in our study all patients who might have been suspected of having CMO on clinical grounds had positive fluorograms. This suggests that photography using oral fluorescein is an adequate test for clinical CMO.

Results of our pilot study would suggest that it is possible to obtain a high proportion of good single frame photographs through pseudophakos and incompletely dilated pupils. We have also shown that 
for the detection of clinical CMO oral fluorescein and single frame photography is an adequate substitute which may avoid some of the pitfalls of intravenous injection.

This work is partly supported by the National Institutes of Health Grant No. EYO 2677-(1)3. We thank Mr D. Barbour for photographic help. Mrs A. Ambrose for technical assistance, and Mrs M. E. Platts for secretarial help.

\section{References}

I Hitchings RA, Chisholm IH. Incidence of aphakic macular ocdema. BrJ Ophthalinol 1975; 59: 444-50.
2 Miyake K. Prevention of cystoid macular oedema after lens extraction by topical indomethacin II: A'control study in bilateral extractions. Jpn J Ophthalmol 1978; 22: 80-94.

3 Noble M, Cheng H, Jacobs P. Salmon J. Long term follow up of intraocular Iens implants. In press.

4 Stark WJ, Maumenec AE, Dangel ME, Martin NF, Hirst LW. Intraocular Ienses. Experience at the Wilmer Institute. Ophthalınology 1982; 89 (2): 104-8.

5 Wade A. ed. Martindale extra pharmacopoeia. 27th ed. London: Pharmaceutical Press, 1977.

6 Kelley JS. Kincaid M. Retinal fluorography using oral fluorescein. Arch Ophthalmol 1979; 97: 2331-2.

7 Araic M, Sawa M, Nagataki S, Mishima S. Aqueous humour dynamics in man as studied by oral fluoresccin. Jpn J Ophthalmol 198(); 24: 346-62. 